\title{
A RELAÇÃO DIALÓGICA ENTRE O MESTRE E O DISCÍPULO: PARA UMA APOLOGIA DO BEM-VIVER FRATERNAL*
}

\author{
THE DIALOGIC RELATIONSHIP BETWEEN MASTER AND DISCIPLES: \\ APOLOGY FOR THE FRATERNAL WELL LIVE
}

\author{
Alberto Filipe Araújo** \\ José Augusto Ribeiro ${ }^{* * *}$
}

\section{RESUMO}

Este artigo discute à luz do "bem-viver" a relação dialógica, que se pretende fraternal, entre o Mestre e o discípulo numa aceção ampla à luz do valor pedagógico do discurso falado e do lugar do Mestre na formação do discípulo e da própria humanidade. Trata-se de valorizar uma pedagogia que faz do diálogo comprometido o leitmotiv fundante cuja pedra angular é a palavra iniciática, enquanto trans-formação (um-bildung) e enfatiza a importância de Olhar o Outro não como um "menor", não como o "estrangeiro", mas na qualidade do meu próximo à semelhança da parábola evangélica do "Bom Samaritano". Assim, afirma a condição itinerante do ser humano (homo viator), realça a simbólica do gesto fraternal, mostra a importância do diálogo realizado ao longo do caminho e as repercussões pedagógicas desta perspetiva. O tema da iniciação e da palavra assumem um papel relevante no processo de conscientização e crescimento em humanidade, onde não pode ser esquecida a dimensão renovadora da pedagogia e a necessidade da presença iniciática de um Mestre ao longo da vida do educando.

Palavras-chave: relação dialógica, bem-viver, itinerância, educação, mestria.

\footnotetext{
* Este texto, em coautoria, é o resultado de uma intervenção realizada, pelo primeiro autor deste artigo, num colóquio intitulado "O sagrado, as espiritualidades e o imaginário na educação" realizado na Universidade Católica de Pernambuco no quadro do "Programa de Pós-Graduação em Ciências da Religião" no dia 3 de novembro de 2015, entre as $14 \mathrm{~h} 30 \mathrm{e}$ as $17 \mathrm{~h} 00$.

** Doutor em Educação (1994) pela Universidade do Minho (Braga-Portugal). Atualmente é Professor Catedrático do Instituto de Educação da Universidade do Minho (Braga- Portugal). Membro efetivo do Centro de Investigação em Educação (CIEd) do Instituto de Educação da Universidade do Minho. Campus de Gualtar, 4710-057 Braga-Portugal; afaraujo@ie.uminho.pt

*** Mestre em Ciências da Educação (2012). Atualmente prepara as a sua Tese de Doutoramente no âmbito da Educação e Pós-Modernidade. É investigador colaborador do projeto de investigação "Educação e Imaginário" sob a direção do Professor Doutor Alberto Filipe Araújo. Rua Nossa Senhora das Graças, n 36, 4700-281, Braga-Portugal; jauribeiro@gmail.com
} 


\section{Abstract}

In this article the author discusses in the light of the idea of "good living" the dialogic relationship, that is intended to be fraternal, between the Master and the Disciple in a broad sense in the light of the pedagogical value of the spoken word and the place of the Master in the formation of the disciple and of humanity itself. It's about enhancing pedagogy that makes the committed dialogue the founding leitmotiv whose cornerstone is the initiatory word as trans-formation (um-bildung) and emphasizes the importance of the Gaze of Others not as "minor", not as "foreigner", but in the quality of my "neighbour" like the Gospel parable of the "Good Samaritan". Thus it asserts the traveling condition of the human being (homo viator), it highlights the symbolism of the brotherly gesture, it shows the importance of dialogue carried out along the way and the pedagogical implications of this perspective. The theme of initiation and word play an important role in the process of awareness and growth in humanness, in which it cannot be forgotten the renewing dimension of pedagogy and the need for the initiatory presence of a Master over the life course of the disciple.

Keywords: dialogic relationship, good living, roaming, education, mastery.

\section{INTRODUÇÃO ${ }^{1}$}

Numa sociedade governada pela autoridade da tecnociência e obcecada pelo desenvolvimento económico e pela eficácia, assistimos a um progressivo desencantamento do mundo. A educação sofre o impacto negativo das transformações sociais e tecnológicas, o computador pode ensinar e transmitir conhecimentos. Contudo, só o Mestre pode despertar o que de melhor existe em nós, induzindo o amor ao conhecimento, apelando ao sonho e à dignidade da pessoa humana. Neste sentido, o valor pedagógico do discurso falado ganha um novo fôlego e a relação entre o Mestre e o discípulo torna-se determinante para a instrução do espírito humano e para a formação do indivíduo. Daí que enfatizemos, e apelemos mesmo, à necessidade da abertura autêntica e comprometida ao Outro, como um TU. Para que a educação possa readquirir um sentido mais profundo enquanto iniciação aos grandes símbolos da Tradição, e não como uma mera didática de procedimentos, do tipo técnico-instrumental, que inelutavelmente conduzem àquilo que Neil Postman designa pelo "fim da educação" e ao que Olivier Reboul chama de "uma educação sem símbolos".

Este artigo valoriza uma pedagogia que faz do diálogo apalavrante o leitmotiv fundante cuja pedra angular é a palavra iniciática, enquanto trans-formação (um-bildung) e enfatiza a

\footnotetext{
${ }^{1}$ Esta publicação teve o apoio financeiro da FCT (Fundação para a Ciência e a Tecnologia - Lisboa - Portugal) e do programa de financiamento POCH (Programa Operacional Capital Humano): financiamento comparticipado pelo Fundo Social Europeu e por fundos nacionais do MEC (Ministério da Educação e da Ciência - Lisboa Portugal) (2015-2016).
} 
importância de Olhar o Outro não como um "menor", não como o "estrangeiro", mas na qualidade do meu próximo à semelhança da parábola evangélica do "Bom Samaritano". Neste sentido, nunca é de mais realçar a importância do bem-viver fraternal, do acolhimento e do perdão numa perspetiva do existencialismo cristão em que imperativo do acolhimento, o dom da escuta e do acompanhamento se impõem tão naturalmente como um gesto de boa vontade. Neste contexto, este estudo trata, na sua primeira parte, da condição itinerante do ser humano (homo viator), enfatiza a simbólica do gesto fraternal, mostra a importância do diálogo realizado ao longo do caminho e as repercussões desta perspetiva na pedagogia. Na segunda parte, estuda a educação e a iniciação no processo de conscientização e crescimento em humanidade, abordando a dimensão renovadora da pedagogia e a necessidade da batuta iniciática de um Mestre no trajeto formativo de cada educando.

\section{COMO O BEM-VIVER FRATERNAL ESTÁ AMEAÇADO E DO SEU ANTÍDOTO}

A "boa vida", no imaginário social da sociedade dos tempos hipermodernos, encontra-se identificada com o poder e utilidade da riqueza e aquilo que esta permite consumir ao nível dos bens materiais, assim como a garantia do conforto, do prolongamento da própria vida ${ }^{2}$, de uma prosperidade sem limites, além de tudo fazer para realizar a satisfação dos desejos privados do sujeito. Numa palavra, a pós-modernidade valoriza unidimensionalmente a dimensão do "ter" consubstanciado em bens de consumo e hedonísticos, suportados por uma moral relativista. $\mathrm{O}$ "ter" passou a ser o novo dogma da vida pós-moderna, esquecendo o ideal da "Vida Boa" consagrado predominantemente pela modalidade do "ser" na linha que Erich Fromm desenvolve na sua obra Ter ou Ser (1987). O "ter" tem marcado, nas suas mais variadas expressões, de modo obsessivo a agenda dos tempos hipermodernos que a todos nos implica direta ou indiretamente. O "ter" é cantado e glorificado pelas mais diversas formas de capitalismo liberal avançado, as quais se assemelham, cada vez mais, a uma "nova religião" (uma espécie de doutrina secular de tipo sacrossanto e salvífico). Uma "nova religião" que, em nome do progresso, da perfetibilidade e da felicidade na terra, prometia a bem-aventurança de uma "boa vida" (sinónimo para nós de "bem-estar") ilustrada, por exemplo, pela "Terra da Cocanha" (1567) de Pieter Bruegel, o Velho, e pela "Terra da Brincadeira" das Aventuras de Pinóquio (1883) de Carlo Collodi.

\footnotetext{
${ }^{2}$ Lembrando aqui os mitos de Frankenstein, de Drácula e o mitologema do elixir da juventude ou a "fonte da juventude" enquanto símbolo de imortalidade ou de rejuvenescimento eterno.
} 
Neste contexto, os arautos do "boa vida" não se cansam de propagar demagogicamente a ideia que a "boa vida" e o "bem-estar" confundidos, no sentido consumista e materialista dos termos, estariam inexoravelmente ao alcance de todos num presente que seria já amanhã e não num futuro, Um amanhã cantado por novos amanhãs, parafraseando aqui o clássico aforismo comunista de "Os novos amanhãs que cantam", pelos valores da pós-modernidade que se tornaram o farol luminoso, uma espécie de "Boa Nova", para que milhões de seres humanos possam, num já amanhã, recuperar uma "boa vida". No entanto, aquilo que a história recente tem mostrado é que os progressos económicos e tecnológicos têm, paradoxalmente, contribuído para que a desigualdade, a injustiça social e a pobreza continuem a aumentar a um ritmo alucinante e não, como seria suposto, diminuído de forma plausível.

Assim sendo, aquilo que pretendemos é possibilitar uma maior consciencialização crítica desta questão insidiosa sobre a promessa de um "boa vida (e de "viver bem") que não deve jamais confundir-se coma noção de "Bem Viver", sinónimo para nós de "Vida Boa". Se à luz dos ideais do "justo meio" (Aristóteles) e do "otium cum dignitate" (Cícero) poderíamos tecer o desenvolvimento deste estudo, preferimos, antes, confecionar um antídoto à luz da tradição cristã e do próprio existencialismo onde o próximo é encarado na qualidade de um "TU", de um rosto que vive nas veredas da vida.

\section{O MESTRE COMO COMPANHEIRO DE VIAGEM}

A instrução e a formação exigem um guia, um Mestre capaz de orientar o discípulo no plano do intelecto e da conduta, possibilitando a construção de um sentido e a compreensão de si mesmo. O nosso ponto de partida começa precisamente com o encontro No caminho de Emaús e a aproximação do Mestre dos Mestres:

Nesse mesmo dia, o primeiro da semana, dois dos discípulos iam a caminho de uma aldeia chamada Emaús, que ficava a cerca de duas léguas de Jerusalém; e conversavam entre si sobre tudo o que acontecera. Enquanto conversavam e discutiam, aproximou-se deles o próprio Jesus e pôs-se com eles a caminho; os seus olhos estavam impedidos de o reconhecer. Disse-lhes Ele: "Que palavras são essas que trocais entre vós enquanto caminhais?" Pararam entristecidos. E um deles, chamado Cléofas, respondeu: "Tu és o único forasteiro em Jerusalém a ignorar o que lá se passou nestes dias?" Perguntou-lhes Ele: "Que foi?" Responderam-lhe: "O que se refere a Jesus de Nazaré, profeta poderoso em obras e palavras diante de Deus e de todo o povo; como os sumos-sacerdotes e os nossos chefes o entregaram, para poder ser condenado à morte e crucificado (Lc 24, 13-20). 
A condição de homo viator (MARCEL, 1963) é realçada por muitos outros autores, mesmo quando, como Daniel Hameline, afirmam que "Nós somos todos viajantes porque nós somos todos obrigados a caminhar sem que o saibamos porquê" (HAMELINE, 1986, p.130). A condição itinerante dos homens traduz-se, segundo este autor, num dos mais velhos gestos do mundo, que é o de "indicar o caminho a um desconhecido, e para isso desviar-se da sua própria direção e acompanha-lo uma parte do seu trajeto" (1980, p. 130). Assim sendo, "a condição itinerante expõe-nos a perdemo-nos, mas também a prestar ajuda; ela implica também que nós possamos ser chamados, por sua vez, a tornarmo-nos guias” (1986, p. 131).

Daniel Hameline reconhece mesmo que o exemplo dado transborda a semântica inerente ao sentido próprio dos mecanismos da linguagem, postulando já um outro nível semântico mais profundo e, consequentemente, enraizado na linguagem do mito:

Dizer da condição educativa pela condição itinerante, é inscrevê-la numa narrativa que é já por si simbólica: a vida humana é aí lida como um itinerário. Esta simbólica oferece o duplo caráter de ser largamente atestada no nosso património cultural, mesmo no fundo antropológico comum a todas as culturas, mas também de convir singularmente à situação presente, tal como nós a somos conduzidos a imaginá-la. Dizer o destino dos homens utilizando a imagerie [no original] do percurso do itinerário, da viagem, é retomar as imagens que a linguagem do mito amplamente utilizou em numerosas culturas, bem como a linguagem da vida espiritual ou moral, seja ela cristã ou pagã, ocidental ou oriental (1986, p.131).

A imagem da "condição itinerante" do homem chama a atenção para a "condição educativa" enquanto caminho de formação plasmado num poema dos «Proverbios y cantares» do livro Campos de Castilla (1912) de Antonio Machado (1875-1939):

Caminhante, são teus rastos/o caminho, e nada mais;/caminhante, não há caminho,/faz-se caminho ao andar./Ao andar faz-se o caminho,/e ao olhar-se para trás/vê-se a senda que jamais se há-de voltar a pisar./Caminhante, não há caminho,/somente sulcos no mar (MACHADO, 1999, p.130).

A simbólica da condição itinerante é igualmente rica de implicações mítico-simbólicas, especialmente quando a esta condição se junta "o mais velho gesto do mundo" que é aquele gesto que nós vemos relatado na Parábola do Samaritano, que responde à pergunta "Quem é o meu próximo?":

Certo homem descia de Jerusalém para Jericó e caiu nas mãos dos salteadores que, depois de o despojarem e encherem de pancadas, o abandonaram, deixando-o meio morto. Por coincidência, descia por aquele caminho um sacerdote que, ao vê-lo, passou ao largo. Do mesmo modo, também um levita 
passou por aquele lugar e, ao vê-lo, passou adiante. Mas um samaritano, que ia de viagem, chegou ao pé dele e, vendo-o, encheu-se de compaixão...Qual destes três parece ter sido o próximo daquele homem que caiu nas mãos dos salteadores? Respondeu: "O que usou de misericórdia para com ele". Jesus retorquiu: "Vai e faz tu também o mesmo" (Lc 10, 29-37).

Vemos aqui retratado o gesto do samaritano que se torna próximo de alguém, que lhe é desconhecido, pela ação do seu gesto solidário e fraternal. Fazemo-nos, sim, próximo de alguém pela nossa ação do encontro e pela disponibilidade que sentimos para o encontro para lá de toda a mediação ou mesmo de todo o critério social estabelecido.

Paul Ricoeur (1968, p. 99-111) realça que, nesta parábola, a misericórdia e a compaixão surgem na e pela dialética do "socius e do próximo" que tomam necessariamente conta da pessoa: o sacerdote e o levita representam a categoria do socius, ou seja, encarnam o "homem da história" (1968, p. 104), enquanto o samaritano representa o próximo. Segundo Ricoeur, o problema não reside em queméo próximo, mas quem se comportou como próximo, pois este é um comportamento e não um objeto: "Não se tem um próximo; faço-me o próximo de qualquer um" (1968, p. 100).E o samaritanoé alguém que está aberto para o outro, sem estar preso a papéis, a cargos, a tradições e a conveniências: "O samaritano é também uma categoria, se se quiser; mas aqui é uma categoria para os outros: é para o judeu pio, a categoria do estrangeiro; não faz parte do grupo (...) É a categoria da não-categoria" (1968, p. 100).

O samaritano é alguém livre da hipocrisia e do cálculo, alguém disponível para a relação eu-tu, no sentido buberiano (1938). O samaritano, ao contrário dos demais, faz-se próximo da vítima, do despojado, enquanto o sacerdote e o levita presos ao seu papel e função sociais (socius) não conseguem sentirse próximos e, por consequência, não conseguem estabelecer um diálogo movido pela compaixão do gesto e pelo olhar favorável e acolhedor do "menor", ou seja, da vítima despojada:

[O samaritano] Não está ocupado; não está preocupado por causa de suas ocupações; está em viagem, não se acha debaixo do peso de seu encargo social, pronto a mudar de caminho e a inventar uma condutaimprevista; disponível para o encontro e a presença. E a conduta que ele inventa é a relação direta "de homem a homem". Esta mesma conduta é da ordem do evento, pois se faz sem mediação de uma instituição; assim como o samaritano é uma pessoa pela sua capacidade de encontro, toda a sua 'compaixão' é um gesto para além do ofício (1968, p. 100).

Deste modo, podemos dizer que o próximo não se esgota numa mera definição, extravasa-a porque refere-se antes ao comportamento efetivo de se tornar presente a alguém. Não basta, assim, dizer que tenho um próximo, mas faço-me efetivamente próximo de alguém pelo meu gesto de tornar-me 
presente pela minha própria práxis que, por sua vez, institui um paradigma de ação. Deste modo, esse alguém de quem efetivamente me aproximei de forma pessoal, é o único referencial para se saber do próximo. Faço-me então próximo pelo gesto da compaixão, da solidariedade e pelo olhar favorável que, na sua plenitude, acolhe o desconhecido transformado num irmão de misericórdia!

O samaritano ao contrário do sacerdote e do levita é o excluído social, o estrangeiro. É o anónimo que, a troco de nada, oferece ao outro não somente a sua ajuda material mas também, e é aquilo que mais importa, todo o seu amor, toda a sua disponibilidade para além de toda a mediação social. O outro (a vítima) é encarado pelo samaritano como o seu próximo enquanto categoria ética e esta não deixa de colocar a questão do comportamento e da atitude que mantém toda a densidade e envergadura da caridade relativamente ao nosso próximo, seja ele estrangeiro, conhecido ou socius:

É preciso, pois, dizer alternativamente: é a História - e sua dialética do próximo e do socius - e sua dialética do próximo e do socius - que mantém a envergadura da caridade; mas é finalmente a caridade que governa a relação ao 'socius' e a relação ao próximo, dando-lhes uma intenção comum. Pois a teologia da caridade não poderia ter extensão menor do que a teologia da História (RICOEUR, 1968, p. 111).

Um samaritano que ia no mesmo caminho-percurso-itinerário e que, sem se desviar do caminho, em vez de o ter continuado ou mesmo de ter fingido de não o ter visto, parou e ajudou o homem anónimo caído semimorto e despojado. A sua categoria é não ter categoria: figura de quem socialmente não tem categoria nenhuma, ou seja, está livre de qualquer encargo social e por isso é "o homem do remorso, do sonho, do mito" (1968, p. 104). É-nos dito que está em viagem, pronto a abrir-se ao imprevisto do encontro e do socorro solidário: "o companheirismo em que o essencial da relação humana reside na troca recíproca e a precariedade dos papéis: quem se engana pode um dia socorrer; quem socorre pode, amanhã, perder-se" (HAMELINE, 1986, p. 132).E a ser assim, a "condição itinerante" dos homens convoca "um dos mais velhos gestos do mundo" (lembramos o texto do nosso começo), e ao fazê-lo deixa já as margens seguras da metáfora para navegar no rio caudaloso da semântica luxuriante do símbolo, cujas funções educativas são postas em evidência por Olivier Reboul (1992). E se o símbolo, como nos ensinou Paul Ricoeur (1988, p.479-488), “dá que pensar” na poética, na psicanálise e na história das religiões também não dá menos que pensar nas designadas Ciências da Educação, particularmente nas disciplinas que tradicionalmente as constituem, tais como a pedagogia 
geral, a psicologia, a sociologia, a história e a filosofia da educação (REBOUL, 1992, p. 200201).

No tocante à Filosofia da Educação, coube a Olivier Reboul (1990, p. 116, 1992, p. 191-219) ter sido o primeiro a dar-se conta que "uma educação sem símbolos face a símbolos sem educação":

Se a educação se conforma aos símbolos, ela reduz-se ao conformismo; (...) Mas se ela os ignora, ela mutila-se porque o homem não pode passar sem eles. É preciso, portanto, conhecê-los em todos os sentidos do termo 'conhecer': fazê-los conhecer, considerá-los, como também fazê-los compreender em toda a sua riqueza polissémica. Que valores simbolizam o lobo e o cordeiro da fábula. Quando a educação negligencia os símbolos, os media apoderam-se deles - tal desportista, tal canção, tal cantor - mas sem incitar minimamente a refletir sobre eles. Uma educação sem símbolos face a símbolos sem educação... (1990, p. 116).

Por outras palavras, "uma educação sem símbolos face a símbolos sem educação" tenderia a reduzir a reflexão filosófica educacional a uma espécie de beco sem saída especialmente por duas razões:

- A primeira é que uma educação sem símbolos tornar-se-ia ininteligível porque se a vocação originária da educação consiste, por um lado, em formar o sujeito pela cultura geral e específica, por outro lado também visa iniciá-lo ao mundo dos valores e é aqui que surge a importância do símbolo como linguagem dos valores (1992, p.191-219);

- A segunda razão é que os símbolos carecem de uma educação de tipo iniciático para melhor revelarem a sua profundidade cosmológica, poética e onírica e não se ficarem num mero nível didático de explicação como acontece, tantas vezes, com a alegoria e mesmo até com a metáfora.

Face às razões agora assinaladas, importa destacar que elas contêm já em si todo um programa hermenêutico-pedagógico prometedor que urge ser levado a sério pela complexa razão que a Natividade ilustra aquilo que pode ser uma educação pelo símbolo, ou seja, graças às qualidades deste passa-se “dos valores sociais aos valores humanos” (1992, p. 217). E a passagem da Natividade conduz-nos quer à compreensão dos valores universais da humanidade, quer àqueles que são caraterísticos da paideia grega (JAEGER, s.d., p.3-18). É portanto toda a simbólica da Natividade, com todas as implicações éticas e mítico-religiosas, que faz do símbolo um "grande 
meio de ensino" (REBOUL, 1992, p. 201) que visa libertar em cada homem aquilo que o “impede de ser ele próprio, de realizar-se conforme o seu 'génio' singular” (1990, p. 22). E este mesmo "génio singular" diz-se, dá-se e afirma-se pela fala que sempre "define uma instância suprema da pessoa, a última palavra, ou a primeira, da existência na sua espontaneidade, testemunho do ser singular que se afirma e reafirma à face do mundo" (GUSDORF, 1995, p. $105)$.

Para que cada homem tenha maiores possibilidades de realizar-se conforme o seu "génio singular" importa que não descure os sentidos do seu caminho de modo a que não se sinta tentado a perder-se nos vários labirintos da vida com todas as consequências que daí resultam. Por isso é o sujeito contemporâneo (evitando aqui a querela concetual da pós-modernidade) que deve restaurar o ritual iniciático como via trans-formadora (Umbildung) do homo viator (MARCEL, 1963) para melhor apreender a via iniciática dos símbolos e não se ficar tãosomente pela sua abordagem meramente didática.

\section{EDUCAÇÃO E INICIAÇÃO: A TRANS-FORMAÇÃO DO DISCÍPULO}

O papel do Mestre é determinante no despertar do conhecimento. Este promove o acesso aos valores e à cultura, mas, fundamentalmente, possibilita ao discípulo a consciência de si mesmo, através de um processo de trans-formação. A condição de descoberta decorre do ritual iniciático, entendido como via trans-formadora (Umbildung). O Mestre assume um papel crucial na Bildung do sujeito moderno e tem grandes repercussões numa pedagogia que se pretende iniciática e remitologizadora, além de ocupar um lugar-chave no imaginário educacional (ARAÚJO \& ARAÚJO, 2009). A substância dos cenários iniciáticos situa-se no plano da imaginação: "quer dizer que eles transmitem agora a sua mensagem espiritual num outro plano da experiência humana, dirigindo-se diretamente à imaginação" (ELIADE, 1976, p. 266). É importante ver que a expressão “diretamente" pode prestar-se a mal-entendidos, pois, e Mircea Eliade sabe-o, há sempre mediação. Interessa, contudo, destacar que a iniciação, enquanto experiência arquetipal típica de toda a existência humana autêntica, não é exclusiva do homem tradicional, pois está sempre ao alcance do homem de hoje reativar, em determinadas condições existenciais e em determinadas etapas da vida, o seu esquema arcaico. 
Compete, assim, a uma pedagogia iniciática e remitologizadora ensinar a reativar o schème (DURAND, 1992, p. 61 ${ }^{3}$ ) arcaico da iniciação para que o sujeito possa ultrapassar as suas crises existenciais num esforço de recuperar novamente a confiança perdida na vida, a sua vocação, o seu destino. Por outras palavras, que o sujeito aprenda a olhar a morte como um "novo nascimento" que visa já realizar o desejo da transmutação espiritual sentida pelo ser humano de todos os tempos e de todas as culturas. O sujeito sente o apelo da mudança e da transformação, é habitado, diríamos, por uma nostalgia de uma renovação iniciática, para se tornar um homem mais realizado, logo mais verdadeiro, o que significa mais espiritual: “Aquilo que se sonha e espera nesses momentos de crise total, é de obter uma renovação definitiva e total, é de obter uma renovatio que possa transmutar a existência. É numa tal renovatio que culmina toda a conversão religiosa autêntica" (ELIADE, 1976, p. 282). De acordo com Mircea Eliade o homem moderno, independentemente da sua crença, experiencia, em determinados momentos da sua existência, uma nostalgia por uma renovação de tipo iniciático.

Por fim, o desiderato de toda a educação, que se pretende iniciática, deve, seguindo os ensinamentos do labirinto, criar condições para que aprendamos a aprender, e a melhor compreender, a profundidade que somos. Somente a compreensão do sentido de profundidade que a imagem matricial do labirinto comporta nos poderá ajudar a romper com as máscaras sob as quais nos escondemos aos outros e a nós mesmos. Torna-se pois tão importante, como urgente, romper esse muro que nos impede de aceder "à consciência do infra-eu, espécie de cogito subterrâneo, de um subsolo em nós, o fundo do sem fundo" (BACHELARD, 1986, p. 260).

Este "fundo do sem fundo", lembrando o mito em Fernando Pessoa, "um nada que é Tudo", parece-nos bem ilustrado pelo mitologema, ou símbolo do labirinto, que, através da sua função iniciática, conduz-nos para os insondáveis caminhos da trans-descendência, na feliz expressão de Gaston Bachelard (1986, p.60). Entre a anábase e a catábase, decide-se muito da nossa Bildung, que acontece sempre na e pela Umbildung do eu nos labirintos da vida, em que os fios de Ariadne estão sempre à espreita, embora, tantas vezes, carecendo de uma pedagogia da escolha e de um Mestre, que não de um professor, que a saiba eleger: "Professores há muitos; mestres, dignos desse nome, raros o são. A palavra consagra, agora, uma qualificação especial,

\footnotetext{
${ }^{3}$ Mantivemos esta noção no original francês em virtude de não haver correspondência na língua portuguesa. A palavra "esquema" que aparece muitas vezes como tradução de schème não colhe pela simples razão que a tradução francesa de "esquema" é a de schéma.
} 
uma força superior, de cuja presença e irradiação irão beneficiar todos os que com ela contactam" (GUSDORF, 1973, p.10). A vida de um Mestre "impõe-se, a todos ou a alguns, como uma lição de humanidade" (1970, p. 10). E todo o Mestre procura, pela palavra e pelo seu exemplo, ir ao encontro do Outro, enfim do seu discípulo (1970, p. 183-204), numa exigência de autenticidade para melhor dar uma lição de humanidade a todos o que com ele contactavam e, particularmente, com os seus discípulos (1970, p 237-265). Nunca esquecendo que é pelo diálogo e pela linguagem que, como nos ensinou Georges Gusdorf, "o ser do homem é levado à consciência de si próprio - abertura para a transcendência” (1995, p. 12). No entanto, é necessário compreender-se que se trata de uma palavra dada, como uma espécie de revelação do ser iluminante da existência do Outro, que exige o respeito dessa mesma palavra. O gesto de dar a palavra, como o Mestre o faz, marca sempre a vida pessoal daquele que a ouve, seja o discípulo iniciado ou um mero neófito. É por isso mesmo que

O homem capaz de dar a sua palavra, encontra-se pois revestido de uma dignidade profética. Perante o futuro desconhecido, a palavra formula uma antecipação: traça, entre a indecisão das circunstâncias, os primeiros contornos do futuro. No seu universo pessoal, o homem intervém com um poder de iniciativa criadora. (...) A palavra transforma a face da situação, é o penhor e compromisso, a assinatura de um contrato que pode parecer uma alienação da liberdade, mas que, na verdade, consagra a ascensão do homem a uma liberdade nova pela virtude da obediência (1995, p. 106).

Se assim for, perguntamo-nos se o viandante, ao longo do caminho nas sendas do mundo e do seu percurso existencial, não necessitará ele também de "dar a sua palavra”, qual "água da vida", para cumprir a sua vocação ontológica de Ser Mais (lembrando aqui Paulo Freire), se não terá ele necessidade de eleger uma pedagogia do caminho sob a batuta iniciática de um Mestre. Trata-se de uma pedagogia que escolha uma bebida salvífica e regeneradora como é a "água da vida" (lembrando "A Fonte da Juventude”), para evocar aqui o "Diálogo com a Samaritana":

Chegou, pois, a uma cidade da Samaria, chamada Sicar, perto do terreno que Jacob tinha dado ao seu filho José. Ficava ali o poço de Jacob. Então Jesus, cansado da caminhada, sentou-se, sem mais, na borda do poço. Era por volta do meio-dia. Entretanto, chegou certa mulher samaritana para tirar água. Disse-lhe Jesus: 'Dá-me de beber'. Os seus discípulos tinham ido à cidade comprar alimentos. Disse-lhe então a samaritana: 'Como é que Tu, sendo judeu, me pedes de beber a mim que sou samaritana?' É que os judeus não se dão bem com os samaritanos. Respondeu-lhe Jesus: 'Se conhecesses o dom que Deus tem para dar e quem é que te diz: 'dá-me de beber', tu é que lhe pedirias, e Ele havia de dar-te água viva!' Disse-lhe a mulher: 'Senhor, não tens sequer um balde e o poço é fundo... Onde consegues, então, a água viva? 
Porventura és mais do que o nosso patriarca Jacob, que nos deu este poço donde beberam ele, os seus filhos e os seus rebanhos?' Replicou-lhe Jesus: 'Todo aquele que bebe desta água voltará a ter sede; mas, quem beber da água que Eu lhe der, nunca mais terá sede: a água que Eu lhe der, há-de tornar-se nele em fonte de água que dá a vida eterna'. Disse-lhe a mulher: 'Senhor dáme dessa água para eu não ter sede, nem ter de vir cá tirá-la.» Respondeu-lhe Jesus: 'Vai, chama o teu marido e volta cá'. A mulher retorquiu-lhe: 'Eu não tenho marido' (Jo 4, 5-15).

Esta passagem do evangelho de S. João diz-nos que Jesus, cansado da caminhada, pediu água a uma mulher samaritana. O Seu gesto de pedir água ${ }^{4}$ introduz-nos numa semântica de proximidade, de cumplicidade e de ligação. E esta ligação, que implica sempre uma dialogicidade entre um eu e um tu (BUBER, 2007), faz-nos pensar novamente na reflexão de Paul Ricoeur sobre o tema do "socius e do próximo", acima evocada, e do tema da misericórdia em que o Outro (a samaritana) na sua alteridade é acolhido por Cristo como um seu semelhante. Por este gesto, que envolve sempre um olhar favorável e acolhedor, Cristo oferece o seu perdão e a sua misericórdia à samaritana que se sente supostamente culpada. É, portanto, através da simbólica do olhar e da palavra comprometida que nos aproximamos da compreensão do eu para o tu orientado, senão mesmo modelado, pela misericórdia. Trata-se pois de um olhar e de uma palavra que não congelam o ser do tu, mas que, pelo contrário, o conseguem perturbar de modo a que ele se abra ao Outro e por esta abertura se torne, por conseguinte, mais disponível. E consegue tornar-se mais disponível, mais misericordioso, mais solidário pela dádiva de si e pela palavra dada envolta numa ética do respeito pela palavra devida: "Cumprir a sua palavra é esforçar-se por conservar um certo sentido de si mesmo, que se reconhece ser constitutivo da existência pessoal. [...] O homem de palavra não promete exageradamente, mas paga com a sua pessoa" (GUSDORF, 1995, p.106-108).

Por isso, é um gesto prototípico que, por sua vez, nos convida a focarmo-nos no símbolo da água. Não se trata de uma água qualquer, pois trata-se de uma água clara (simboliza a limpidez e transparência natural) e fresca de um poço (BACHELARD, 1993, p. 29-56).A água clara, de acordo com Gaston Bachelard, representa "um símbolo natural para a pureza; ela dá sentidos precisos a uma psicologia prolixa da purificação. (...) é uma tentação constante para o simbolismo fácil da pureza. (...) Pela purificação, participa-se numa força fecunda, renovadora, polivalente" (1993, p. 153-154 e p. 163). Neste contexto, com Mircea Eliade, podemos dizer que a chamada "água da vida" é o protótipo da água (que, por sua vez, reenvia para o outro

\footnotetext{
${ }^{4}$ Muito haveria a discorrer sobre o valor ontológico deste gesto como metáfora solidária, do perdão e da humildade.
} 
símbolo capital - a "árvore da Vida" de que fala o Apocalipse, 22, 1-2) e, como tal, é "fonte da vida" e "símbolo da vida": a "Água da Vida" é o "Símbolo cosmogónico, receptáculo de todos os gérmenes, a água torna-se na substância mágica e medicinal por excelência; ela cura, rejuvenesce, assegura a vida eterna" (ELIADE, 1994, p. 237).

A “Água Viva”, de que fala Cristo, sublinha o caráter purificador, curativo e rejuvenescedor da “Água Viva” (como água clara, límpida, fresca, pura, maternal e feminina que é - Bachelard, 1993, p.132-152) que dá a vida eterna àquele ou àquela que dela beber: "Todo aquele que bebe desta água voltará a ter sede; mas, quem beber da água que Eu lhe der, nunca mais terá sede: a água que Eu lhe der há-de tornar-se nele em fonte de água que dá a vida eterna" - são as palavras do Cristo à Samaritana.

A referência à "fonte de água que dá a vida eterna" reenvia imediatamente para a "Árvore da Vida", atrás referida, e para a "Fonte da Juventude" (a fontaine de Jovence). A água proveniente dela possui efeitos rejuvenescedores e purificadores e harmoniza o tema da imortalidade com o da eterna juventude. Acredita-se que a água, que dela brota, tenha o poder de curar os males dos enfermos e de rejuvenescê-los (veja-se o exemplo das águas minerais e termais). Neste sentido, o doente bebendo a água da "fonte" espera não só ficar curado, mas também vitalizado, ou seja, mais energizado e, por conseguinte, mais jovem: "Ela [a água da fonte] desperta os centros nervosos. Ela tem uma composição moral. Ela desperta o homem para a vida enérgica" (BACHELARD, 1993, p. 168).

O doente espera salvar-se e rejuvenescer-se (que se torne mesmo imortal) bebendo da água mágica e salvífica da fonte. E porquê? Porque trata-se de uma água que é um leite: "toda a água é um leite" diz Gaston Bachelard (1993, p. 135), daí a crença que a água, tal como o leite, alimente e dê saúde aos fracos e aos enfermos. Além disso, a água, à semelhança do leite, é doce revigorante e tonificante: "A água doce será sempre na imaginação dos homens uma água privilegiada" (1993, p. 179). Uma água doce e maternal "que faz viver na morte, além da morte" diz Carl Gustav Jung! E não foi isto mesmo que Cristo procurou transmitir à Samaritana? Darlhe a beber da "Água Viva" para lhe saciar a sua sede espiritual e permirtir-lhe viver para além da morte? Sabemos bem que a "vida eterna" anuncida por Cristo no seu diálogo com a Samaritana não é a imortalidade que os enfermos mortais ansiavam obter bebendo da água da "Fonte da Juventude", mas se encararmos este tema não só como uma lenda, mas também como 
uma metáfora, à semelhança de Gaston Bachelard (1993, p. 166), entender-se-á mais pertinentemente a sua "pregnância simbólica" e mesmo o seu alcance espiritual.

Trata-se de uma “Água Viva” eufemizadora capaz de combater o tempo e de transmutar o peso trágico da morte, pelo que, aqui, nos cruzamos com uma das funções capitais da Imaginação a da eufemização e que, segundo Gilbert Durand, consiste em lutar "contra a podridão, exorcismo da morte e da decomposição temporal" (1992, p. 472). Por outras palavras, importa que saibamos merecer também beber da "Água Viva e da Vida" como uma água consoladora ou da consolação. Que seria de nós peregrinos, viandantes, sem esta água consoladora ao longo dos caminhos da nossa existência? Que seria de nós sem uma samaritana (eis o nosso próximo!) que dê de beber da água do poço ao Mestre dos Mestres, lembrando aqui a figuras do Mestre cantadas por Georges Gusdorf (Professores para quê?), Georges Steiner (As Lições dos Mestres) e Karl Jaspers (Os Mestres da Humanidade)? E que Este, por sua vez, lhe fale da “Água da Vida" como aquela água que dá a Vida eterna no lugar de apagar simplesmente uma sede fisiológica e momentânea, pois como Cristo disse: "Todo aquele que bebe desta água voltará a ter sede; mas, quem beber da água que Eu lhe der, nunca mais terá sede: a água que Eu lhe der há-de tornar-se nele em fonte de água que dá a vida eterna”.

E não será portanto esta “Água Viva” uma consolação que nos ajudará a usar da Palavra ao longo dos caminhos da Vida entrecortados pelas paisagens da existência? Por fim, para recordarmos novamente a figura de Paulo Freire, não será a “Água Viva” um forte estimulante e contributo para que a nossa vocação ontológica de Ser Mais se torne o Graal da nossa condição de peregrinos ? Não será também esta "Água" aquela que ajudava aqueles viandantes que, à semelhança dos reis magos, perscrutavam os céus para melhor se reencontrarem ?

\section{CONCLUSÃO: PARA UMA APOLOGIA DO BEM-VIVER FRATERNAL}

Uma apologia do bem-viver fraternal assume atualmente uma relevância tão intensa que o desenvolvimento das ideias anteriores não cessam de contribuir para que a relação do Mestre e do discípulo possa não ser somente refigurada à luz do valor pedagógico da palavra iniciática, como também à luz da relação dialógica do eu e do tu numa perspetiva marcadamente existencialista cristã.

Sentirmo-nos disponíveis para um "tu” torna-se mais compreensível à luz da relação do Mestre com o discípulo. Se, por um lado, esta relação "é um diálogo sem comunicação, uma comunhão 
indireta e sem plenitude, uma fuga cuja solução e resolução será indefinidamente recusada" (GUSDORF, 1973, p. 316), por outro lado o Mestre exprime-se pelo dom da palavra iniciática porque tem como uma das suas principais missões libertar no seu discípulo aquilo que o impede de ser ele mesmo e levá-lo a descobrir o seu destino ou o seu caminho: "Há no mundo um único caminho que ninguém pode seguir a não ser tu. Onde conduz ele? Não o perguntes. Segue-o" (NIETZSCHE, 1922, p. 11). Por outras palavras, o Mestre assume-se como um educador que sabiamente cria condições para o discípulo realizar, como dissemos citando Olivier Reboul, o seu "génio singular" na procura incessante da verdade, visto que aquele educador, no sentido de Mestre e não de professor ou mesmo de pedagogo, que cultiva a verdade "irradia uma luz que remete cada um para si mesmo, forçando-o a julgar-se. (...) A sua linguagem exerce uma eficácia intrínseca que leva à adesão dos outros” (GUSDORF, 1995, p. 108-108).

E como é que um Mestre realiza a sua missão? É verdade que cada Mestre tem o seu estilo singular e a sua visão do mundo - lembre-se Guilherme de Baskerville do Nome da Rosa de Umberto Eco (1980), o Mestre de Música da Ordem de Castália, e mesmo Joseph Knecht, da obra O Jogo das Pérolas de Vidro de Hermann Hess (1943), a figura do barqueiro do Sidarta (1922) do mesmo autor, assim como o Velho Monge do filme de Kim Ki-duk intitulado Primavera, Verão, Outono, Inverno... e Primavera (2003) -, mas pode-se realçar algumas características comuns na missão de todos eles: a iniciação pelo silêncio, pela música, pelo diálogo, pelo olhar, pela escuta, pelo uso terapêutico e catártico da palavra: "O grande educador é aquele que espalha em torno de si o sentido de honra da linguagem, como uma preocupação de integridade na presença neste mundo e dentro de si próprio" (GUSDORF, 1995, p. 108). O Mestre vê a unidade e a harmonia além das diferenças, tem o dom da profecia e do sacrifício e concebe a humanidade na sua unidade universal. A este respeito, importa realçar, com Georges Gusdorf, que "A mestria começa para lá da pedagogia. A mestria supõe uma pedagogia da pedagogia” (1973, p. 309). Assim, compreende-se que a palavra iniciática é usada com mestria não pelo que é mero educador ou professor, mas por uma espécie de eleitos, isto é, por todos aqueles que veem além da pedagogia. Neste sentido, o Mestre sabe que é sempre, em certo sentido, um eterno discípulo aberto ao mundo da sabedoria, da vida, dos valores, do mistério e do mundo. Por isso, é que "Faz-lhe horror o espírito de proprietário do pedagogo, e a sua segurança na vida" (1973, p. 310).

O Mestre sabe que o epicentro da educação reside na relação de confiança, de partilha e de confidência estabelecida incessantemente entre o mestre e o discípulo, daí que ele seja um 
iniciador dos valores e da cultura. O Mestre deve, quanto a nós, assumir-se especialmente como um despertador de consciências e suscitador de reflexões profundas em direção à eudemonia (JAEGER, s.d., p. 497-498) e à liberdade: “O despertar da reflexão consagra o advento do homem para si mesmo. Ele descobre então a sua mais alta liberdade, isto é, a sua mais pessoal liberdade" (GUSDORF, 1973, p. 313).Esta liberdade sempre se busca, conquista-se ao longo das veredas do destino de cada um quando se abre mão do epíteto de Mestre: "Mas aquele que renunciou a descobrir a mestria da terra dos homens, esse pode um dia encontrá-la viva e a acenar-lhe, na volta do caminho, sob disfarce mais imprevisto" (1973, p. 318). E esta é a condição para que um Mestre seja re-conhecido e aceite como tal, pela simples razão de que a “mestria é um mistério" (1973, p. 316) insondável revelado àquele que a merece e que não a ganha simplesmente pelo fruto das circunstâncias ou por supostas ações meramente terrenas. Por último, importa sempre não esquecer que alguém só se torna Mestre, um ungido, um escolhido, graças aos seus dons e boas-ações praticadas com o "menor", com o "desconhecido", com o "desvalido" apedrejado e abandonado pelos salteadores deste mundo enfermos de humanidade (ANDERS, 2011, 2011 ). Por outras palavras, não é Mestre quem quer ou quem se julga ser, mas tão-somente aqueles que são reconhecidos como tal e também aqueles que acharam Graça aos olhos do Divino!

\section{REFERÊNCIAS BIBLIOGRÁFICAS}

ANDERS, Günther (2011). La Obsolescencia del Hombre. Sobre el alma en la época de la segunda revolución industrial. Vol. I. Trad. de Josep Monter Pérez. Valencia: Pre-Textos.

$\left(2011^{\mathrm{a}}\right)$. La Obsolescencia del Hombre. Sobre la destrucción de la vida en la época de la tercera revolución industrial. Vol. II. Trad. de Josep Monter Pérez. Valencia: Pre-Textos.

ARAÚJO, Alberto Filipe \& ARAÚJO, Joaquim Machado de (2009).Imaginário

Educacional. Figuras e Formas. Niterói: Intertexto, 2009.

BACHELARD, Gaston. La Terre et les Rêveries du Repos. Paris: Librairie José Corti, 1986. 1993.

L'Eau et les Rêves. Essai sur l'imagination de la matière. Paris. LibraireJosé Corti,

BUBER, Martin. Je et tu. Trad. de Geneviève Bianquis. Paris: Aubier-Montaigne, 1938.

Do Diálogo e do Dialógico. São Paulo: Perspectiva, 2007.

DURAND, Gilbert. Les Structures Anthropologiques de l'Imaginaire. 11. ed. Paris:

Dunod, 1992.

ELIADE, Mircea. Initiation, rites, sociétés secrètes. Paris: Gallimard, 1976. 
Tratado de História das Religiões. Trad. de Natália Nunes e Fernando Lisboa. Edições Cosmos, 1997.

GUSDORF, Georges. Professores para quê? Para uma pedagogia da pedagogia. Trad. de João Bernard da Costa e António Ramos Rosa. Lisboa: Moraes editores, 1973.

A Palavra. Função-Comunicação-Expressão. Trad. de José Freire Colaço. Lisboa: Edições 70, 1995.

HAMELINE, Daniel. L'Éducation, ses Images et son Propos. Paris: Éditions ESF, 1986.

JAEGER, Werner. Paideia. A Formação do Homem Grego. Trad. de Artur M. Parreira. Lisboa: Editorial Aster, s. d.

MACHADO, Antonio. Campos de Castilla. s/l: Editorial Literanda, 2012.

MARCEL, Gabriel. Homo Viator: Prolégomènes à une métaphysique de l'Espérance. Paris: Aubier, 1963.

NIETZCHE, Friedrich. Considérations Inactuelles. 6. ed. Vol. 5, Tome 2. Paris: Mercure de France, 1922.

REBOUL, Olivier (1990). La Philosophie de L'Éducation. 2. ed. Paris: PUF, 1990. . (1992). Les valeurs de l'éducation. Paris: PUF, 1992.

REPUSSEAU, Jean. Homo docens. Réflexions sur l'action pédagogique et la formation des maîtres. Paris: Armand Colin, 1972.

RICCEUR, Paul. História e verdade. Trad. de F. A. Ribeiro. Rio de Janeiro: Companhia Editora Forense, 1968.

Philosophie de la volonté. II - Finitude et culpabilité. Paris: Aubier, 1988. 